\title{
Compelling therapy of LVH: straight (and not-so-straight) inferences from evidence
}

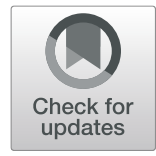

\author{
Ravi Tejraj Mehta* ${ }^{*}$, Anil Pareek and Shruti Dharmadhikari
}

\begin{abstract}
We have read with interest the Korean Society of Hypertension guidelines for the management of hypertension and congratulate the Society for an extensive review of literature while drafting the guidelines. The guidelines indicate preferring ACE-I and CCB over diuretics in patients with left ventricle hypertrophy. However, in landmark head-to-head comparison trials, the thiazide-like diuretic chlorthalidone has been shown to be superior to ACE-I and CCB in decreasing left ventricle mass and preventing heart failure in hypertensive patients. Also, we put forth the paradoxical finding that mere regression of LVH may not always translate into reduction in risk of HF; and that the pleiotropic effects of chlorthalidone may be the explanation behind its beneficial action in HF.
\end{abstract}

Keywords: Guidelines, Chlorthalidone, Amlodipine, Hypertension, Left ventricle hypertrophy, Heart failure, Thiazide diuretics, Calcium channel blockers, ACE-inhibitors

\section{Dear Editor}

We have read with interest the Korean Society of Hypertension guidelines for the management of hypertension: part II-diagnosis and treatment of hypertension by Lee HY, et al. [1] and congratulate the Society for an extensive review of literature while drafting the guidelines. We wish to stress upon the importance of HTN control as stated in the Guidelines - 'The purpose of HTN treatment is to prevent CVD caused by increased BP and to reduce mortality by controlling high BP'. However, we would like to put forth following comments on clinically-crucial aspects of hypertension management:

1. It is well established that chronically increased LV workload in hypertensive patients triggers cardiac remodelling, development of $\mathrm{LVH}$, increased risk of heart failure with preserved ejection fraction (HFpEF) and heart failure with reduced ejection fraction (HFrEF) and, ultimately, death [2, 3]. Thus, HT induces a compensatory thickening of the ventricular wall to normalize wall stress, which results in LV concentric hypertrophy, leading to decrease in the LV compliance and LV diastolic filling. This diastolic dysfunction has been

\footnotetext{
* Correspondence: ravi.mehta@ipca.com

Ipca Laboratories Limited, Kandivli Industrial Estate, Kandivli (West), Mumbai, Maharashtra, India
}

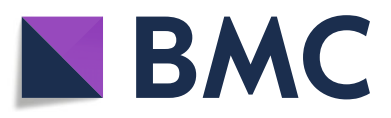

(c) The Author(s). 2019 Open Access This article is distributed under the terms of the Creative Commons Attribution 4.0 International License (http://creativecommons.org/licenses/by/4.0/), which permits unrestricted use, distribution, and

reproduction in any medium, provided you give appropriate credit to the original author(s) and the source, provide a link to the Creative Commons license, and indicate if changes were made. The Creative Commons Public Domain Dedication waiver (http://creativecommons.org/publicdomain/zero/1.0/) applies to the data made available in this article, unless otherwise stated. recognised as a component of diastolic heart failure and a critical link between hypertension and heart failure [4]. Till date, there is no successful therapy for diastolic heart failure and strategies directed towards prevention of this progression from hypertension to LVH and subsequent HFpEF hold the greatest promise for reducing the burden of HF.

2. Table 11 in the Guidelines [1] titled 'Compelling indications for choosing the antihypertensive drugs' describes appropriate drugs according to the patient's combined risk factors and co-morbidities. In this table, left ventricular hypertrophy (LVH) has been denoted as a compelling indication for ACE-I/ ARBs and calcium channel blockers (CCBs). Surprisingly, diuretics have not been marked indicating a preference of these agents over diuretics in patients with LVH. However, landmark NIHsponsored hypertension trials have clearly demonstrated superiority of the thiazide-like diuretic chlorthalidone (CTD) over ACE-I and CCB in reduction of left ventricle mass (LVM) and prevention of HF.

The Treatment of Mild Hypertension Study (TOMHS) assessed the effect of five antihypertensive monotherapies (CTD, acebutolol, doxazosin, amlodipine and enalpril) on reduction of LVM in 902 patients with "mild" (stage 1) hypertension [5]. After 4 
years of treatment, all 5 therapies showed reduction in LVM from baseline; but only CTD declined LVM significantly more than placebo. Average decreases ranged from $34 \mathrm{~g}$ for participants given CTD to $23 \mathrm{~g}$ for participants given enalapril and $25 \mathrm{~g}$ with amlodipine $(P=0.05$ for difference among the five drug-treatment groups). It was also observed that CTD caused a significantly larger decrease in LV internal dimension at end diastole compared to other drug treatments $(P=0.02)$ including amlodipine. ALLHAT (Antihypertensive and Lipid-Lowering Treatment to Prevent Heart Attack Trial), the largest randomized hypertension outcomes trial $(n=42,418)$, provides another head-to-head comparison between CTD, ACE-I lisinopril and the CCB amlodipine [6]. After a mean follow-up of almost 5 years, although there was no difference between treatments on the primary outcome (combined fatal CHD or nonfatal myocardial infarction), the most intriguing finding of ALLHAT has been the significantly lower rates of HF events in the CTD group compared to both CCB and ACE-I. The amlodipine group had 38\% higher risk of HF $(P<0.001)$ and $35 \%$ higher risk of hospitalized/fatal HF $(P<0.001)$ as compared to CTD. The lisinopril group had 19\% higher risk of HF $(P<0.001)$ and $10 \%$ higher risk of hospitalized/fatal HF $(P=0.11)$ as compared to the CTD group. These results held true when examined across the predefined subgroups of age, race, sex, diabetes status and by absence or presence of CHD at baseline. Remarkably, the Kaplan-Meier event curves for patients hospitalized for HF or death due to HF begin to separate immediately after randomization, with relative risk of 2.22 (95\% confidence interval [CI], 1.69-2.91; $P<.001)$ for amlodipine vs. CTD in the first year and of 2.08 (95\% CI, 1.58-2.74; $P<.001)$ for lisinopril vs. CTD [7].

Apart from TOMHS and ALLHAT, treatment with CTD has been associated with favourable changes in LVH in several other landmark hypertension trials, including the Hypertension Detection and Follow-Up Program (HDFP), the Systolic Hypertension in the Elderly Program (SHEP), and the Multiple Risk Factor Intervention Trial (MRFIT) [8-10].

3. The LVH-HF Paradox:

The direct cardiac effect of LVH includes an increased risk of developing congestive heart failure and the associated morbidity and mortality [11]. Thus, one of the major objectives in achieving regression of $\mathrm{LVH}$ and reduction of LV mass is to reduce the incidence of $\mathrm{HFpEF}$ and HFrEF and the allied hospitalisations and death. However, reduction in LVH may not always translate into direct reduction in incidence of diastolic dysfunction and HF. The examples of this are perhaps amlodipine and the RAAS inhibitors. In the ASCOT-BPLA (Anglo-Scandinavian Cardiac Outcomes Trial-Blood Pressure Lowering Arm) study, amlodipine \pm perindopril arm vs. atenolol \pm bendroflumethiazide resulted in significant reductions in several secondary endpoints except fatal and non-fatal heart failure [12]. In a recent sub-study of ASCOT, it was seen that, despite regression of $\mathrm{LVH}$, there was no associated improvement in diastolic function with amlodipine \pm perindopril-based therapy [13]. Similarly, while inhibition of the RAAS has been shown to be beneficial in the treatment of patients with systolic HF, RAAS blockade in the prevention and treatment of HFpEF has been disappointing. In a sub-analysis of the ALLHAT, the thiazide-like diuretic CTD was shown to significantly reduce the risk of HFpEF by 31 and $26 \%$ compared to amlodipine and lisinopril, respectively [corresponding HRs and 95\% CIs were 0.69 $(0.53-0.91 ; p=0.009)$ and $0.74(0.56-0.97 ; p=0.032)$ ] [14]. Further, perindopril in PEP-CHF (Perindopril in Elderly People with Chronic Heart Failure), candesar$\tan$ in CHARM-Preserved (Candesartan in Heart failure: Assessment of Reduction in Mortality and morbidity) and irbesartan in I-PRESERVE (Irbesartan in Heart Failure with Preserved Ejection Fraction Study) have all failed to show any significant difference vs. placebo in reducing the primary outcome of death and HF-related hospitalization in patients with HFpEF [15-17].

4. An interesting recent analysis of the ALLHAT dataset looked at the extent to which the effect of an anti-hypertensive on incident HF is mediated by evolving LVH. The researchers found that the beneficial effects of CTD in reduction of HF were entirely independent of evolving $\mathrm{LVH}$, leading them to postulate that that the mechanisms by which chlorthalidone prevented HF were not restricted to prevention of LVH [3]. In contrast to other antihypertensives and diuretics, CTD has unique pleiotropic properties including improving endothelial function, reducing inflammatory and oxidative stress, inhibition of platelet aggregation and vascular permeability, and promotion of angiogenesis [18]. These features probably impart CTD a distinctive advantage to not only effectively reduce the BP and $\mathrm{LVH}$, but also prevent progression to HFpEF and ultimately HF.

5. Other hypertension guidelines: Finally, it is important to discuss similar recommendations from other recent hypertension guidelines.

a. The ACC-AHA 2017 Guidelines [19] state that "LVH is a secondary manifestation of hypertension and independently predicts future CVD 
events. BP lowering leads to a reduction in LV mass. In TOMHS (Treatment of Mild Hypertension Study), the long-acting diuretic chlorthalidone was slightly more effective in reducing LVH than were a calcium channel blocker (CCB) (amlodipine), ACE inhibitor (enalapril), alpha-receptor blocker (doxazosin), or beta-receptor blocker (acebutolol). Beta blockers are inferior to angiotensin receptor blockers (ARBs), angiotensin converting enzyme (ACE) inhibitors, and CCBs in reducing LVH."

b. The ESC-ESH 2018 Guidelines while discussing left ventricular hypertrophy and heart failure observe that "Treating hypertension has a major impact on reducing the risk of incident heart failure and heart failure hospitalization, especially in old and very old patients. This has been observed using diuretics, beta-blockers, ACE inhibitors, or ARBs, with CCBs being less effective in comparative trials. Reducing BP can also lead to the regression of $\mathrm{LVH}$, which has been shown to be accompanied by a reduction of $\mathrm{CV}$ events and mortality. The magnitude of LVH regression is associated with baseline LV mass, duration of therapy, the SBP reduction, and the drugs used, with ARBs, ACE inhibitors, and CBBs causing more effective $\mathrm{LVH}$ regression than beta-blockers or diuretics" [20]. However, the guideline authors do not provide any reference for stating RAS blockers or CCBs as superior over diuretics. They do cite a reference for superiority over beta-blockers.

c. Canada Hypertension Guidelines 2018 recommend that in treatment of $\mathrm{HT}$ in association with LVH "Initial therapy can be drug treatment using ACE inhibitors, ARBs, longacting CCBs, or thiazide/thiazide-like diuretics. Antihypertensive treatment should include an agent from one of the five major classes in patients with $\mathrm{LVH}$, with care given to the inferiority of $\beta$-blockers in patients with LVH" [21].

d. The 2016 National Heart Foundation of Australia Guidelines [22] state that "In a metaanalysis of differences between antihypertensive treatments, heart failure was more likely to occur in those given calcium channel blockers compared to those given diuretics, ACE inhibitors or beta-blockers. A network meta-analysis involving 223,313 patients published in 2011 also reported diuretics as the most effective class of drugs in preventing heart failure".

To summarize, we wish to highlight that data from head-to-head landmark studies suggests that CTD has superior effects than ACE-I and CCBs in reduction of LV mass and risk of HF amongst hypertensive patients. We have raised similar concerns about CCBs in diabetic hypertensive patients with diastolic dysfunction - thiazide-like diuretics should be preferred ahead of CCBs for blood pressure control in such patients to prevent HF [23]. Similarly, in view of the discussed evidence, we urge the Korean Society of Hypertension to relook at and suitably amend their recommendations for hypertensive patients with $\mathrm{LVH}$.

\section{Abbreviations \\ ACC-AHA: American College of Cardiology and American Heart Association; ACE-I: Angiotensin converting enzyme inhibitors; ALLHAT: Antihypertensive and Lipid-Lowering Treatment to Prevent Heart Attack Trial; ARB: Angiotensin Receptor Blocker; CCB: Calcium Channel Blocker; CTD: Chlorthalidone; ESC-ESH: European Society of Cardiology and European Society of Hypertension; HF: Heart failure; HFpEF: Heart failure with preserved ejection fraction; HFrEF: Heart failure with reduced ejection fraction; \\ HTN: Hypertension; LVH: Left ventricular hypertrophy; NIH: National Institutes of Health; RAAS: Renin-angiotensin-aldosterone system; TOMHS: Treatment of Mild Hypertension Study}

\section{Acknowledgements}

Not applicable.

\section{Authors' contributions}

RM conceived and drafted the manuscript. AP and SD revised the manuscript. All authors read and approved the final manuscript.

\section{Funding}

There is no funding for this work.

Availability of data and materials

Not applicable.

Ethics approval and consent to participate

Not applicable.

Consent for publication

Not applicable.

\section{Competing interests}

Authors are affiliated to Ipca Laboratories Limited and are involved in research studies on chlorthalidone.

Received: 28 August 2019 Accepted: 18 October 2019

Published online: 15 November 2019

\section{References}

1. Lee HY, Shin J, Kim GH, et al. 2018 Korean Society of Hypertension Guidelines for the management of hypertension: part II-diagnosis and treatment of hypertension. Clin Hypertens. 2019;25:20.

2. Williams B, Mancia G, Spiering W, et al. ESC Scientific Document Group 2018 ESC/ESH Guidelines for the management of arterial hypertension. Eur Heart J. 2018:39(33):3021-104.

3. Johnson K, Oparil S, Davis BR, et al. Prevention of Heart Failure in Hypertension-Disentangling the Role of Evolving Left Ventricular Hypertrophy and Blood Pressure Lowering: The ALLHAT Study. J Am Heart Assoc. 2019;8(8):e011961.

4. Lalande S, Johnson BD. Diastolic dysfunction: a link between hypertension and heart failure. Drugs Today (Barc). 2008;44(7):503-13.

5. Neaton JD, Grimm RH Jr, Prineas RJ, et al. Treatment of mild hypertension study. Final results. Treatment of mild hypertension study research group. JAMA. 1993;270(6):713-24.

6. ALLHAT Officers and Coordinators for the ALLHAT Collaborative Research Group. The Antihypertensive and Lipid-Lowering Treatment to Prevent Heart Attack Trial. Major outcomes in high-risk hypertensive patients 
randomized to angiotensin-converting enzyme inhibitor or calcium channel blocker vs diuretic: the antihypertensive and lipid-lowering treatment to prevent heart attack trial (ALLHAT). JAMA. 2002;288(23):2981-97.

7. Davis $B R$, Piller $L B$, Cutler JA, et al. Role of diuretics in the prevention of heart failure: the antihypertensive and lipid-lowering treatment to prevent heart attack trial. Circulation. 2006;113(18):2201-10.

8. Hypertension Detection and Follow-up Program Cooperative Group. Five-year findings of the hypertension Detection and follow-up program. Prevention and reversal of left ventricular hypertrophy with antihypertensive drug therapy. Hypertension. 1985;7:105-12.

9. Ofili EO, Cohen JD, St Vrain JA, et al. Effect of treatment of isolated systolic hypertension on left ventricular mass. JAMA. 1998;279:778-80.

10. Ernst ME, Neaton JD, Grimm RH Jr, et al. Long-term effects of chlorthalidone versus hydrochlorothiazide on electrocardiographic left ventricular hypertrophy in the multiple risk factor intervention trial. Hypertension. 2011; 58:1001-7.

11. Kahan T. The importance of left ventricular hypertrophy in human hypertension. J Hypertens Suppl. 1998 Sep;16(7):S23-9.

12. Dahlöf B, Sever PS, Poulter NR, et al. ASCOT Investigators. Prevention of cardiovascular events with an antihypertensive regimen of amlodipine adding perindopril as required versus atenolol adding bendroflumethiazide as required, in the Anglo-Scandinavian Cardiac Outcomes Trial-Blood Pressure Lowering Arm (ASCOT-BPLA): a multicentre randomised controlled trial. Lancet. 2005;366(9489):895-906.

13. Barron AJ, Hughes AD, Sharp A, et al. ASCOT investigators. Long-term antihypertensive treatment fails to improve E/e' despite regression of left ventricular mass: an Anglo-Scandinavian cardiac outcomes trial substudy. Hypertension. 2014;63(2):252-8.

14. Davis BR, Kostis JB, Simpson LM, et al. Heart failure with preserved and reduced left ventricular ejection fraction in the antihypertensive and lipid-lowering treatment to prevent heart attack trial. Circulation. 2008;1 18(22):2259-67.

15. Cleland JG, Tendera M, Adamus J, et al. PEP-CHF investigators. The perindopril in elderly people with chronic heart failure (PEP-CHF) study. Eur Heart J. 2006;27(19):2338-45.

16. Yusuf S, Pfeffer MA, Swedberg K, et al. CHARM investigators and committees. Effects of candesartan in patients with chronic heart failure and preserved left-ventricular ejection fraction: the CHARM-preserved trial. Lancet. 2003;362(9386):777-81.

17. Massie BM, Carson PE, McMurray JJ, et al. I-PRESERVE investigators. Irbesartan in patients with heart failure and preserved ejection fraction. N Engl J Med. 2008;359(23):2456-67.

18. Roush GC, Buddharaju V, Ernst ME, et al. Chlorthalidone: mechanisms of action and effect on cardiovascular events. Curr Hypertens Rep. 2013;15:514-21.

19. Whelton PK, Carey RM, Aronow WS, et al. 2017 ACC/AHA/AAPA/ABC/ACPM/ AGS/APhA/ASH/ASPC/NMA/PCNA guideline for the prevention, Detection, evaluation, and Management of High Blood Pressure in adults: a report of the American College of Cardiology/American Heart Association task force on clinical practice guidelines. Hypertension. 2018;71(6):e13-e115.

20. Williams B, Mancia G, Spiering W, ESC Scientific Document Group, et al. 2018 ESC/ESH Guidelines for the management of arterial hypertension. Eur Heart J. 2018;39(33):3021-104

21. Nerenberg KA, Zarnke KB, Leung AA, et al. Hypertension Canada. Hypertension Canada's 2018 guidelines for diagnosis, risk assessment, prevention, and treatment of hypertension in adults and children. Can J Cardiol. 2018;34(5):506-25.

22. National Heart Foundation of Australia. Guideline for the diagnosis and management of hypertension in adults - 2016. Melbourne: National Heart Foundation of Australia; 2016.

23. Pareek AK, Mehta RT, Purkait I, et al. Diabetic Hypertensives and diastolic dysfunction: use of Calcium Channel blockers-a clinical concern. JACC Heart Fail. 2017;5(11):850-1.

\section{Publisher's Note}

Springer Nature remains neutral with regard to jurisdictional claims in published maps and institutional affiliations.

\section{Ready to submit your research? Choose BMC and benefit from:}

- fast, convenient online submission

- thorough peer review by experienced researchers in your field

- rapid publication on acceptance

- support for research data, including large and complex data types

- gold Open Access which fosters wider collaboration and increased citations

- maximum visibility for your research: over $100 \mathrm{M}$ website views per year

At BMC, research is always in progress.

Learn more biomedcentral.com/submissions 